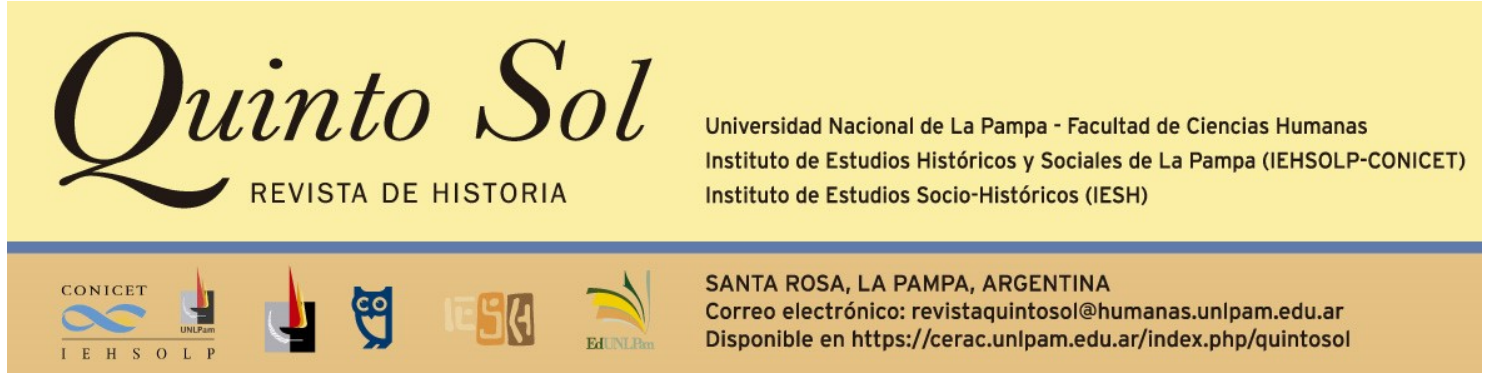

Quinto Sol, vol. 25, n० 1, enero-abril 2021, ISSN 1851-2879, pp. 1-4

http://dx.doi.org/10.19137/qs.v25i1.4554

Esta obra se publica bajo licencia Creative Commons 4.0 Internacional. (Atribución-No ComercialCompartir lgual)

\title{
Silvana Ferreyra y Federico Martocci (Eds.) El Partido Socialista (re)configurado: escalas y desafíos historiográficos para su estudio desde el interior. IEHSOLP (CONICET-UNLPam), IESH (FCH-UNLPam) / Teseo, 2019, 330 páginas.
}

\section{Lucas Poy}

Consejo Nacional de Investigaciones Científicas y Técnicas

Universidad de Buenos Aires. Instituto de Historia Argentina y Americana "Dr. Emilio Ravignani"

Argentina

Correo electrónico: lucaspoy@conicet.gov.ar

Afortunadamente, hace tiempo que dejó de ser novedad destacar que los estudios sobre el Partido Socialista (PS) argentino concitan un creciente interés historiográfico. En los últimos quince años -la publicación de un señero volumen compilado por Hernán Camarero y Carlos Miguel Herrera en 2005 fue sin duda un claro punto de partida- la cantidad de trabajos se ha multiplicado, al tiempo que crece y se diversifica el número de investigadores e investigadoras que abordan la historia de esta fuerza política. La conformación de la Red de Estudios sobre el Socialismo Argentino (RESA), promovida por el propio Herrera y Ricardo Martínez Mazzola, es al mismo tiempo un resultado de este desarrollo y un factor de impulso del mismo. Una de las peculiaridades más notables de este fenómeno historiográfico es que ha mostrado una importante distribución regional, con colegas de muchos puntos del país que desarrollan ya desde hace años un trabajo sistemático en el tema. El volumen 
compilado por Silvana Ferreyra y Federico Martocci marca en este sentido un jalón importante en este proceso de revitalización.

El volumen reúne trabajos presentados originalmente en un taller realizado en Mar del Plata en noviembre de 2018, financiado por la Agencia Nacional de Promoción Científica y Tecnológica y avalado por el Centro de Estudios Históricos de la Universidad Nacional de Mar del Plata, el Instituto de Estudios Socio-Históricos de la Universidad Nacional de La Pampa y la Red de Estudios sobre el Socialismo Argentino RESA-. Además cuenta con un prólogo de Camarero y Herrera y un epílogo de María Liliana Da Orden. En su «Introducción», Ferreyra y Martocci se esfuerzan por ubicar las contribuciones de la compilación en el contexto más general de la literatura sobre el socialismo en Argentina; el texto brinda en este sentido un preciso y detallado estado de la cuestión acerca de la historiografía del socialismo en el «interior» que servirá de referencia futura por un largo período. Los compiladores argumentan allí que tanto las interpretaciones «nativas» -es decir, elaboradas por los propios dirigentes y militantes del PS- como buena parte de las académicas compartieron durante mucho tiempo «una visión desde arriba, homogénea y urbana del PS» (p. 32). Según Ferreyra y Martocci, «los estudios sobre el socialismo en el "interior" contribuyen a reconfigurar el PS al debatir con esa matriz "capitalinocéntrica"»y, al mismo tiempo, pueden ayudar a examinar «las formas específicas de acción política del socialismo, alejándonos así del perfil más iluminista y pedagógico que prevaleció tanto en las interpretaciones críticas como en las partidarias» (p. 34). Esto hace referencia al hecho de que estudios precisos de experiencias locales pueden revelar con mayor exactitud aquellos casos en los cuales «la expansión del PS redundó en acceso efectivo a gobiernos comunales u otras instancias de poder» (p. 45).

En efecto, casi todos los trabajos que componen el volumen son investigaciones que buscan «reconfigurar la historia del PS a partir de análisis situados en territorios concretos» (p. 52). Hay, no obstante, dos excepciones. La primera es el capítulo de Ricardo Martínez Mazzola, que se plantea una escala de análisis más global, tanto en términos cronológicos como geográficos. Se trata de un estudio detallado de los centros representados en todos los congresos partidarios -ordinarios y extraordinariosentre la fundación formal del partido en 1896 y la ruptura de 1958. El trabajo de Fernando Suárez también propone un estudio que va más allá de lo local. En su caso, se trata de un examen de los primeros años del Partido Socialista Popular, en la década de 1970, dedicando especial atención a descifrar la peculiar combinación de «tradiciones políticas» que dieron forma al proyecto liderado por Guillermo Estévez Boero.

Los diez capítulos restantes abordan períodos de tiempo más cortos y espacios geográficos más acotados. La distribución regional y temporal de estos trabajos, en cualquier caso, no es homogénea: más de la mitad de ellos se concentran en localidades de la provincia de Buenos Aires durante el siglo XX. Silvana Ferreyra examina al Partido Socialista Democrático en los primeros años que siguieron a la ruptura de 1958 con eje en Mar del Plata; en tanto Gonzalo Cabezas y Roberto Cimatti abordan la historia del socialismo de Bahía Blanca en las primeras décadas del siglo XX; Luciano Barandiarán y Leonardo Fuentes estudian -en un texto conjunto- la trayectoria del Partido Socialista Independiente en Ayacucho y Tandil durante los años 30 y Andrés Bisso explora la obra de un referente del socialismo democrático en Luján. María Liliana 
Da Orden, en su epílogo, también se concentra en la correspondencia de Nicolás Repetto con dirigentes y militantes marplatenses.

Algunas localidades de las provincias de Santa Fe, Córdoba, La Pampa y Santiago del Estero también reciben atención en el volumen, que incluye estudios de caso sobre las dificultades del socialismo en Rosario en la década de 1910 (Alex Ratto), los desafíos que debió encarar el intendente socialista de la localidad cordobesa de Sampacho tras un terremoto que afectó gravemente a la localidad en 1934 (Karina Martina), la peculiar experiencia de un militante socialista de origen boliviano en los centros socialistas de Santiago del Estero en 1916-1919 (Héctor Daniel Guzmán) y una lectura de las obras de la «serie pampeana» de Pedro E. Pico ambientados en la Santa Rosa de principios del siglo XX (Paula Laguarda y Federico Martocci).

Más allá de sus diferentes recortes cronológicos o espaciales, en las investigaciones que componen el volumen se observan una serie de rasgos comunes, por ejemplo, el trabajo con fuentes habitualmente ignoradas en las obras sobre el PS centradas en Buenos Aires, tales como periódicos locales -tanto partidarios como comerciales-, actas de reuniones de los distintos centros, documentación de congresos provinciales, libros de correspondencia de militantes y dirigentes locales, autobiografías y anecdotarios, e incluso obras teatrales. No faltan, por supuesto, las indispensables referencias a ese gran organizador de toda la vida partidaria que fue La Vanguardia, una fuente que sigue revelando sus potencialidades y demuestra, en este caso, cuánta información puede ofrecer un periódico respecto al socialismo en el interior a pesar de ser editado en la capital por la dirección nacional del partido.

De conjunto, el libro es convincente en su argumento acerca de la necesidad de prestar atención a las peculiaridades locales del desenvolvimiento histórico del socialismo en Argentina a lo largo del siglo XX. El volumen pone de manifiesto, a partir de investigaciones empíricas, que la vida social y política del Partido Socialista argentino era más heterogénea y compleja de lo que parece desde la bibliografía canónica partidaria, la normativa de los estatutos o las directivas emanadas de las autoridades centrales. En el terreno, los centros socialistas locales y muchos de sus militantes y dirigentes conservaban en realidad márgenes de autonomía; en no pocas ocasiones, eso implicó incluso hacerse cargo de los resortes del poder estatal a nivel local.

De todas formas, aunque la introducción de Ferreyra y Martocci indica que una de las apuestas del volumen es «identificar fehacientemente los momentos a partir de los cuales la expansión del PS redundó en acceso efectivo a gobiernos comunales $u$ otras instancias de poder» (p. 45), lo cierto es que los trabajos incluidos en el libro exploran experiencias políticas relativamente débiles: con la excepción del capítulo que analiza la actividad de un intendente socialista en la pequeña localidad cordobesa de Sampacho. El resto de los textos que componen esta publicación no estudia experiencias «de gestión» y tampoco experiencias de crecimiento significativo de las fuerzas socialistas y vínculos con procesos de masas. Cabe señalar, también, que las historias relatadas en el volumen están protagonizadas en su totalidad por varones, acaso con la excepción del trabajo de Martocci y Laguarda que presta especial atención al lugar ocupado por las mujeres en las obras teatrales de Pedro E. Pico. Queda planteado, en una futura agenda de investigación, visibilizar el lugar de las mujeres del PS a escala regional y local, así como una problematización de las relaciones y dinámicas de género en esas escalas. 
El volumen aquí reseñado, en suma, resulta un aporte provechoso a la historiografía del socialismo argentino, que reúne trabajos de más de una decena de colegas que desde hace años vienen animando el panorama historiográfico sobre esta fuerza política. Se trata de un libro que resultará útil tanto para especialistas en la historia social y política de las izquierdas como para el público general interesado en el socialismo argentino; al mismo tiempo, es un aporte a los avances realizados en la tradición de la historia política analizada «desde el interior». Como lo señalan los propios compiladores en su introducción, es también una contribución para sistematizar y ordenar «un conjunto de preguntas que las nuevas investigaciones insinúan para reconfigurar la historia del PS a partir de análisis situados en territorios concretos» (p. 52). 